\title{
Historias cantadas de la guerra: los corridos prohibidos como memoria del conflicto en el Guaviare*
}

Recibido: 03/08/2020 | Revisado: 08/02/2021 | Aceptado: 15/02/2021

DOI: 10.17230/co-herencia.18.34.8

\author{
Daniel Esteban Unigarro** \\ dunigarro@unisalle.edu.co \\ Carlos-Germán van der Linde*** \\ cvanderlinde@unisalle.edu.co
}

\begin{abstract}
Resumen Los corridos prohibidos se han configurado en Colombia como un género musical popular que alude a temáticas relacionadas con el conflicto armado, el narcotráfico y la violencia asociada. Durante una estancia en campo en las selvas del Guaviare se escuchó una composición anónima que narraba la vida problemática de un paramilitar que protagonizó un combate con un guerrillero por el control territorial del mismo lugar. Este hallazgo motivó la indagación sobre el potencial narrativo de este corrido y permitió establecer la existencia de otra composición dedicada al protagonista guerrillero. Así, se presenta un contraste entre ambos corridos a partir del análisis narratológico de las letras transcritas, el cual se ha complementado y confrontado con fuentes documentales e investigación etnográfica para develar la historia cantada y contada de la guerra entre paramilitares y guerrilleros en la zona durante los últimos años del siglo Xx y los primeros del XxI. Se concluye que los corridos prohibidos se constituyen en fuentes para la memoria del conflicto al posibilitar la transmisión y reproducción cotidiana de las historias de guerra que recrean no solo escenas de violencia sino a sus protagonistas como héroes o villanos, es decir, una memoria alternativa para la comprensión diferenciada y situada del conflicto armado colombiano.
\end{abstract}

\section{Palabras clave:}

Guaviare, conflicto armado, corridos prohibidos, guerra, historia, memoria.
* Este artículo es producto del proyecto de investigación "Reconfiguraciones y transiciones para la territorialización: estrategia para la construcción de paz en San José del Guaviare" (código 2438936), financiado por la Universidad de La Salle.

** Profesor de la Universidad de La Salle, Colombia. ORCID: 0000-00026310-0223.

**** Profesor de la Universidad de $\mathrm{La}$ Salle, Colombia. ORCID: 0000-00027229-7689. 


\title{
Stories Sung of War: Forbidden Ballads as a Memory of the Conflict in Guaviare
}

\begin{abstract}
In Colombia, forbidden ballads form a popular musical genre in which songs allude to themes related to the armed conflict, drug trafficking, and associated violence. During a fieldwork to the jungles of Guaviare, we listened an anonymous song that narrated the troubled life of a paramilitary who fought with a guerrilla for territorial control of the same place. This event motivated the study of the narrative potential of this ballad and was used to establish the existence of another composition dedicated to the guerrilla protagonist. Thus, a contrast between both ballads is presented based on the narratological analysis of the transcribed lyrics, which has been complemented and confronted with documentary sources and ethnographic research to unveil the sung and told story of the war between paramilitaries and guerrillas in the area in the late years of the 20th century and the early years of the 21st century. It concludes that the forbidden ballads constitute sources of the memory of the conflict. They enable the transmission and daily reproduction of war stories that recreate scenes of violence and present their protagonists as heroes or villains. That is, they represent an alternative memory for a differentiated and situated understanding of the Colombian armed conflict.
\end{abstract}

\section{Keywords:}

Guaviare, armed conflict, forbidden ballads, war, history, memory.

\section{Buscar la historia y encontrar corridos}

En los caseríos o centros poblados de las áreas rurales de zonas como los Llanos Orientales y la selva amazónica, a pesar de las muchas diferencias que se perciben en el paisaje, un mismo ritmo musical retumba en cada tienda o puesto en el que los visitantes pueden beber algo que les permita refrescarse por la intensidad del calor o la humedad. Los foráneos, incluyendo a investigadores interesados en la historia regional y local, poco acostumbrados al volumen exagerado y los bajos de la música, una vez familiarizados con lo que en principio consideran un ruido excesivo, logran prestar atención a las letras de aquellas coplas o versos que sin querer se empiezan a tararear. Sin embargo, resulta una gran sorpresa escuchar que el trasfondo de aquellas músicas conocidas como corridos no es otro que la realidad de múltiples hechos del pasado en aquellos 
territorios asociados a la colonización campesina, los cultivos de coca, el narcotráfico y la guerra entre los diferentes grupos al margen de la ley: guerrilleros y paramilitares.

Este es el caso de San José del Guaviare, el municipio que funge como capital departamental y sirve de conexión entre los Llanos y la entrada a la selva amazónica colombiana. En torno al casco urbano se gestó una fuerte dinámica de colonización campesina a partir de la década de 1960 (Jimeno, 1987; Marín, 2002), se estableció el grupo armado ilegal denominado Fuerzas Armadas Revolucionarias de Colombia -Farc- y su presencia contribuyó a la consolidación de una economía ilegal basada en el cultivo de coca desde el segundo lustro de 1970 (Molano, 1987; García, 1995). Para finales de 1990, incursionaron los grupos paramilitares (Ardila, 2004), dadas las conexiones y los vínculos que forjó la guerra entre grupos armados al margen de la ley con ideologías diametralmente opuestas, provenientes no solo de departamentos cercanos como Casanare y Meta, sino de regiones como el Urabá (Gómez, 2017), de modo que no importó mucho atravesar medio país para luchar por el mismo propósito aparente de su enemigo: ayudar al pueblo y los campesinos.

Los paramilitares disputaron el control territorial ejercido durante un par de décadas por la guerrilla, y ambos actores armados tuvieron entre 1997 y 2003 una serie de fuertes enfrentamientos armados en los que un gran número de población civil resultó víctima por cuenta de hechos violentos, asesinatos, desapariciones forzadas, masacres y reclutamiento ilegal de menores, entre otros (Ardila, 2004; Equipo Humanitario Colombia, 2013; Gómez, 2017; Verdad Abierta, 2016, 2018). Estos actos de vulneración de derechos en contra de los habitantes rurales hacen parte de los relatos de la guerra que tuvo lugar en el Guaviare y, para bien o para mal, configuran la memoria del conflicto en la zona.

Develar que esta memoria es reconocida y transmitida en los corridos, fue posible cuando de manera inesperada e insospechada durante una estancia corta de trabajo de campo en el caserío de la vereda Charrasquera durante el mes de octubre de 2019, se observó que en la única tienda se repetían una y otra vez los mismos corridos que narraban historias de personajes rudos y valerosos que no 
temían enfrentar a sus enemigos y ejecutar acciones violentas que eran motivo de orgullo. Al indagar sobre esto, se logró establecer que incluso en un corrido se mencionaba el nombre de la vereda y se obtuvo como obsequio por parte del entrevistado un disco compacto sin ninguna marca con 22 pistas, de las cuales se transcribe y analiza en detalle la pista 10 y sirven como apoyo las pistas 3 y 7.1

Este hallazgo permitió incorporar en la investigación un enfoque narrativo desde la música popular que cuenta cantando acontecimientos particulares y complementa las descripciones propias de la investigación cualitativa de corte etnográfico que se nutre de la observación participante y de entrevistas a profundidad, las cuales se han contrastado con investigación documental de fuentes bibliográficas, de prensa y en línea sobre la historia reciente del conflicto en la región. De esta forma, además de complementar y permitir contrastar la historia de guerra del protagonista de la pista 10, se logró identificar al antagonista que es mencionado en el corrido y hace parte del otro bando, de quien también se compuso un corrido que es igualmente transcrito y analizado en su narrativa. Por lo tanto, contrastar ambos corridos prohibidos permite dar cuenta de las narrativas cantadas de la guerra que se vivió en el Guaviare durante los últimos años del siglo Xx y los primeros del XXI.

Así las cosas, en la primera parte se aborda la relación entre memoria histórica y los corridos como género musical popular que da cuenta de narrativas sobre acontecimientos concretos vinculados en el caso colombiano con la violencia, el narcotráfico y el conflicto armado, determinando la emergencia del género de los corridos prohibidos. Después, con base en la transcripción de la pista 10 se analiza la narrativa del corrido desde su protagonista paramilitar, para luego presentar la transcripción del corrido dedicado al comandante guerrillero mencionado y así contrastar las narraciones épicas construidas en torno de ambos protagonistas del conflicto en

\footnotetext{
A pesar de que se intentó la identificación de estas pistas mediante la búsqueda de sus letras, el envío de los archivos de audio y las transcripciones a algunos habitantes de San José del Guaviare, e incluso al productor musical Alirio Castillo, para obtener información sobre el compositor o grupo intérprete, esto no fue posible, de manera que se hace referencia a estas composiciones con el número de pista asignado en el disco compacto.
} 
el Guaviare. Posteriormente, se hace una breve reconstrucción de la historia de la guerra que tuvo lugar en esta área rural como escenario de los enfrentamientos entre guerrilleros y paramilitares, con el propósito de mostrar la capacidad y el potencial tanto narrativo como descriptivo de los corridos analizados. Por último, se concluye sobre la pertinencia del análisis de los corridos prohibidos como fuente para la construcción de la memoria local y regional del conflicto en el país y el análisis de las representaciones de los actores armados en relación con las narrativas cantadas de la violencia.

\section{Los corridos prohibidos: entre la narrativa popular y la memoria del conflicto}

Es la hora de recostar un taburete a la puerta de la calle y empezar a contar desde el principio los pormenores de esta conmoción nacional, antes de que tengan tiempo de llegar los historiadores García Márquez, "Los funerales de la Mamá Grande"

Para el narrador del renombrado cuento de García Márquez (2012, p. 97) que sirve de epígrafe a este acápite, la anticipación a los historiadores señala la existencia de una memoria autóctona de la historia. Una voz popular, por fuera de la ilustración letrada, capaz de narrar y narrarse. Esto, justamente, ocurre con la música gauchesca, villera, protesta y similares de Latinoamérica. De esta producción musical, los corridos resultan excepcionales como receptores de un testimonio popular (Valbuena, 2009). A pesar de las polémicas en torno a su origen griego, al semejar los cantos épicos de gestas y aventuras en tierras insólitas y el mismo inframundo (Páramo, 2009, p. 222); medieval, cuando juglares y goliardos cantaban y contaban las historias no oficiales de lo que acontecía (Friedmann, 2009), como después harían los romances españoles que narraban las actividades ilegales de bandoleros y traficantes, por demás con una métrica y estructura compositiva similar a los actuales (Valbuena, 2006), sin duda el origen moderno de los corridos se sitúa en México. 
La historia y formación del Estado moderno mexicano ha sido memoria popular, de transmisión oral, acompañada de instrumentos de cuerdas como guitarras, bandolones o arpas, o en conjunto por mariachis (Mendoza, 1997, p. 137). Trazar una narrativa de corte popular de la historia es importante porque resulta ser un gesto espontáneo y desintelectualizado de la memoria del pueblo. El carácter popular, en este contexto, significa registrar los sucesos históricos con antelación a la apropiación epistemológica que van a realizar los intelectuales y a la captación ideológica por parte de los partidos políticos y sus gobiernos. La "bola revolucionaria" mexicana es una expresión de la comprensión ética del mundo que responde a un sentido de justicia sin mediación de categorías analíticas. Así lo enseña el personaje campesino levantado en armas, Demetrio Macías, en la novela de la primera década de la revolución mexicana, Los de abajo, de Mariano Azuela (1988). Luis Cervantes se suma a la bola, aparte de compartir la misma perspectiva de justicia, para servir de "traductor", puesto que sería el equivalente a la llegada de los historiadores que anuncia el narrador de "Los funerales de la Mamá Grande", porque su lugar de privilegio académico le permite articular -léase descifrar- los sucesos revolucionarios. En este marco, Macías es la encarnación de la lucha, él es la revolución popular; mientras que Cervantes hace la sistematización y analítica del evento. Cervantes nunca será la revolución, su narrativa es y será siempre una mirada foránea.

Contrario a esa inevitable extranjería de la memoria de Cervantes, el corrido es una expresión orgánica, connatural a lo popular, como se puede observar en la película mexicana El violín, de Francisco Vargas (2005), en la comprensión y transmisión generacional de las gestas libertarias guerrilleras (en alusión a la "guerra sucia" en Chiapas). La tradición oral va del abuelo, don Plutarco (interpretado por un actor natural que le imprime mayor sentido de autenticidad rural), al hijo Genaro y al nieto Lucio. En la novela de Azuela se necesitan dos tipos de personajes muy diferentes para construir una memoria, el revolucionario analfabeto y, llamémoslo así, el "cronista" letrado. En la película de Vargas, las dos funciones son cumplidas por el mismo tipo de personaje: los cantantes-rebeldes, que son sujetos 
populares. Se tiene con ello una memoria desintelectualizada y una versión de los hechos desde adentro del movimiento insurgente.

El corrido, como expresión popular de la cultura, ha servido para contar la épica de las luchas independentistas y revolucionarias (Mendoza, 1997, p. 131). Se posicionó como manifestación propia y autóctona al ser el mecanismo por el cual el sentir del pueblo se manifestó sin que pudiera ser censurado o reprimido, construyó la imagen del héroe de la revolución mexicana como forajido que luchaba por el bienestar de los pobres y desamparados (Pinzón, 2014 , p. 32). Con ello, ha trazado una línea narrativa que consigna los eventos centrales de tales luchas: hazañas, victorias, derrotas, héroes, etcétera. Algo semejante ocurre con las composiciones musicales asociadas al bandolerismo de las décadas de 1950 y 1960 en Colombia, vistas como una estrategia mnemónica para preservar en el recuerdo individual y colectivo a figuras heroicas que encarnaron en la leyenda ideales de justicia y libertad de la época de La Violencia en regiones como el Ariari o el sur del Tolima, donde se conformaron núcleos de guerrilla liberal y de resistencia armada (Mora, 1998, p. 31). De hecho, la forma musical y la estructura del relato de estas memorias musicales campesinas que evocan la vida y las acciones de guerrilleros, bandoleros o bandidos guardan gran familiaridad con los corridos mexicanos tanto por la naturaleza épica y lírica de sus textos como por la forma de sus estructuras musicales que facilitan el relato de historias (Mora, 1998).

Desde luego, las formas musicales del género no están tan arraigadas en Colombia como en México, donde "el corrido perfectamente enraizado en el espíritu de la nación entera [...] surge como manifestación artística de diferentes aspectos, ampliando su radio de acción, desbordándose, por decirlo asî" (Mendoza, 1997, p. 220). Tampoco tiene la dimensión del bambuco o la cumbia, ni ha adquirido dimensiones míticas como el vallenato. No obstante, por la enorme capacidad del género para adaptarse a los cambios en la sociedad y, en particular, a los gustos del público, los corridos de empistolados que tratan de narcotraficantes -y que quizás surgieron por cuenta de las gratificaciones a compositores y cantantes- se han popularizado en cantinas, bares, discotecas, bailes y tiendas de 
discos (López, 1995, p. 15). Así, el narcocorrido adopta y conserva las estructuras de su antecesor y lo llena de nuevos contenidos. Las gestas ya no son político-militares, sino narco-económicas. La guerra de los traficantes de drogas es la nueva épica identitaria que se define por su oposición a la represión militar (Burgos, 2013, p. 169) y al descrédito generalizado hacia el Estado de derecho. En los narcocorridos el sentido de lo popular ha cambiado. En este espectro caben las manifestaciones populares del amplio circuito del tráfico de drogas ilícitas, con sus fetiches, sincretismos, paganismos y folclore, en muchos casos, iconográficos.

La incorporación de temas como el narcotráfico y la violencia haciendo uso de la misma instrumentación basada en acordeón, batería, bajo sexto, bajo y voces, dio lugar de manera simultánea por la contingencia histórica y el contexto particular de emergencia, así como por sus dinámicas y transformaciones, a tres dimensiones del mismo fenómeno: un género musical, un movimiento y una colección, los "corridos prohibidos" (Pinzón, 2014), es decir, "una música de frontera" en constante ambigüedad (Páramo, 2009). Los corridos prohibidos se configuran a partir del contacto cultural transnacional entre México y Colombia (Valbuena, 2009) y como hipertextos basados en los corridos tempranos que harían las veces de hipotextos de muestras musicales, históricamente semejantes, como las que compondrían esa suerte de "cancionero infame colombiano" (Mora, 1998). En esta genealogía musical y narrativa, aquellas producciones mexicanas y colombianas del bandidaje sirven de referentes compositivos, melódicos y dramáticos para los corridos prohibidos. Así, se constata la relación hipertextual de segundo grado (Genette, 1989) del género musical popular y marginal.

En su versión más reciente, los corridos prohibidos se reconocen por sus referencias al narcotráfico, pero en especial vinculándolo con la dinámica del conflicto armado colombiano, que se convierte en su eje narrativo al describir hazañas o hechos trágicos y violentos cometidos por diferentes actores que pocas veces son visibilizados de otra manera. En la forma musical del corrido estas referencias, más que contenidos temáticos, cumplen funciones sociales (Almonacid, 2016b) al distribuir en una trama narrativa 
de villanos y héroes (Almonacid, 2016a) a los principales actores de la violencia del país y sus regiones. Es así como los protagonistas pueden ser no solo grupos genéricos como los raspachines, sino guerrilleros y paramilitares, incluso fácilmente identificables dado que se mencionan sus alias, el frente o bloque armado al que pertenecían o lideraban, y en ocasiones hasta el hecho violento que motivó su reconocimiento. Este atrevimiento que origina la connotación de "prohibidos" permitió que se consolidaran como un género musical en cuanto logra reproducir las características de un contexto social propio y también contribuye a la construcción de realidades y la creación de experiencias entendibles únicamente bajo una identidad subjetiva y colectiva (Vila, 2001). Además, la consolidación de las telecomunicaciones y el fácil acceso a medios de reproducción audiovisual promovió su difusión, circulación alternativa y autopromoción por parte de cantautores e intérpretes (Almonacid, 2016a).

En este sentido, los corridos prohibidos tuvieron gran acogida no solo entre los miembros de los grupos armados al margen de la ley que se vieron representados con la música (Semana, 2010), sino entre los habitantes de las regiones apartadas y zonas marginadas del país y abandonadas por el Estado, donde la dinámica del conflicto era parte de la cotidianidad. Al estar familiarizado con el ritmo y, en especial, al sentirse identificado y verse reconocido en las letras de los corridos, el pueblo sintió que esta música contaba la verdad sobre la guerra en Colombia sin ningún tipo de censura (Pinzón, 2014, p. 23). Como la violencia ha tenido repercusiones en todo el territorio nacional, en particular en las áreas rurales, las cargas culturales fruto de la convivencia con el conflicto permitieron que la música popular cumpliera un rol de memoria e identidad al vincular la creación artística-musical con la evolución histórica del conflicto armado, lo cual se evidencia en las letras que muestran a quienes lo han vivido directamente (Castro, 2018).

La construcción de la memoria del conflicto guarda entonces un vínculo fundamental con la forma en la que se concibe la historia como ciencia del tiempo, no solo para recopilar y analizar los hechos del pasado, sino reconstruir explicaciones para diferentes realidades 
que acontecieron en otros momentos. Por esto, la memoria histórica es "la reconstrucción de los datos proporcionados por el presente de la vida social y proyectada sobre el pasado reinventado" (Betancourt, 1999, p. 18). Esta proyección-reinvención es posible en el caso de los corridos prohibidos, cuando sus letras funcionan como memoria viva y comunicativa de conflictos situados (Almonacid y Burgos, 2018). Es así como los corridos, al revelar las verdades de la guerra difíciles de contar, recuperan y al tiempo se constituyen en testimonios amparados en la univocidad y autenticidad de la experiencia en el relato y en la imposibilidad de acceder a esta por otro medio: "No hay testimonio sin experiencia, pero tampoco experiencia sin narración" (Sarlo, 2006, p. 29). Por tanto, los sujetos que se ven reflejados o viven intensamente los corridos resultan interpelados por la música y esto contribuye a la construcción de su identidad por su fijación como sujetos históricos (Vila, 2001, p. 35).

Como descripción del pasado, los corridos prohibidos también son construcciones discursivas que, si bien no sirven como espejo de la experiencia, contribuyen a crear identidades, reivindicaciones y relaciones siempre cambiantes con el pasado (Pinzón, 2014, p. 19). Por tanto, hacen parte de la memoria colectiva como un cuadro de semejanzas que funciona para un grupo que permanece limitado en el espacio y en el tiempo (Halbwachs, 1995), pero siempre es resultado de procesos sociales y a su vez es constitutiva de prácticas sociales contextualizadas (Visacovsky, 2007). De este modo, en cuanto rememoran los conflictos, crean entornos cotidianos y dan cuenta de múltiples lugares de memoria, los corridos pueden servir como recurso didáctico para tejer una conciencia histórica (Almonacid y Burgos, 2018). Así las cosas, se presentan dos historias cantadas de la guerra que tienen como protagonistas a "dos negros" de bandos enfrentados en un mismo escenario territorial, con el fin de brindar una línea narrativa contrastada del conflicto armado colombiano en una región en la que los corridos prohibidos no solo se escuchan sino se lloran, se recuerdan, se sienten, se sufren, se viven.

Cabe señalar que como la música es susceptible de ser estudiada por métodos de corte cualitativo y es importante hacerlo en su contexto real (Burgos, 2014), en este caso no se privilegia la producción, el uso 
y el consumo de los corridos sino la realidad específica asociada al conflicto armado en el contexto territorial donde se presentan las situaciones descritas. En este sentido, interesan los corridos prohibidos como trabajos discursivos para analizar el punto de vista que adoptan, los asuntos específicos que abordan, la caracterización de los hechos que narran y de los personajes que en ellos participan, la finalidad que parecen perseguir, la ideología que muestran, los juicios que hacen o que callan y las mediaciones que realizan (De la Garza, 2016, p. 24). Por lo tanto, se ha privilegiado un análisis textual de base narratológica (Bal, 1997) que examina las transcripciones desde sus componentes compositivos: el narrador (si este es intradiegético o extradiético), el sistema de personajes y sus focalizaciones, el cronotopo, entre otros, para desde ahí exponer los estratos simbólicos, metafóricos e ideológicos. Esto permite observar las capas miméticas, retóricas y poéticas de los corridos, con lo que se sigue el examen aristotélico empleado para el teatro trágico (Aristóteles, 1988). Posteriormente, este análisis se confronta con fuentes bibliográficas académicas, de prensa, testimonios y entrevistas, para efectuar una descripción densa (Geertz, 1992) sobre la memoria del conflicto evocada y registrada en los relatos de los corridos.

\section{"Del Urabá pa' la selva": la "causa" popular del "Negro Tayson"}

Urabá es el topónimo del área de influencia del golfo homónimo en la que confluyen los departamentos de Antioquia, Córdoba y Chocó. Además de la gran riqueza natural y cultural, su posición geográfica sobre el mar Caribe y la cercanía con el Pacífico le otorga gran importancia como eje de conexión legal e ilegal de todo tipo de flujos, lo cual en términos económicos siempre ha sido aprovechado y también disputado. Su proceso de configuración territorial ha estado marcado por dinámicas de acumulación por desposesión promovidas por la expansión y consolidación del paramilitarismo, que tuvo allí una suerte de estado fundacional para estos grupos armados ilegales responsables de la expulsión violenta del campesinado de sus tierras, el asesinato, la homogenización 
del panorama político y la flexibilización violenta del trabajo en la región (Lombana, 2012). Sin embargo, su actuar no se limitó a esta región y para el último lustro del siglo XX el paramilitarismo se desplaza a las selvas del Guaviare:

El ingreso de paramilitares provenientes de Urabá a Mapiripán y la masacre de civiles ocurrida en julio de 1997 en este territorio, marcaron un importante punto de inflexión en la dinámica del conflicto armado de esta región. Su ingreso tuvo lugar inicialmente en veredas como Charras, Charrasquera y Guanapalo, acción que se consolidó en el año 2000 con la conformación del Bloque Héroes del Guaviare, el cual desplegaba diferentes acciones criminales en los cascos urbanos de El Retorno, Calamar y San José, así como en las veredas cercanas a dichas cabeceras y a lo largo del eje vial que une a esos últimos dos municipios. La llegada de los paramilitares al Guaviare se presentó luego de que los hermanos Castaño le vendieran su "franquicia" de las AUC [Autodefensas Unidas de Colombia] a Miguel Arroyave, alias Arcángel, que junto a Daniel Rendón, alias 'Don Mario', controló territorialmente el negocio de la droga entre esta región y el sur del Meta, por medio del Bloque Centauros (Defensoría del Pueblo, 2019).

Este es un contexto general para entender la narrativa del corrido de la pista 10, que hace memoria de la gesta paramilitar desde un extremo ideológico y presenta al guerrero "paraco" como su gran héroe. A continuación, se reproduce el corrido con una convención que emplea números romanos para identificar las estrofas y números latinos para los versos:

[0] 1. ¡Y por el Urabá!

[I] 2. Yo vengo del Urabá

3. me trasladaron por bueno

4. y me mandaron mis jefes

5. pa' los Llanos Orientales.

6. Ahora me encuentro en la selva

7. de San José del Guaviare.

[II] 8. Me apodan El Negro Tayson

9. es como me han conocido, 
10. mi nombre me lo reservo

11. pues tengo mucho enemigo.

12. Hay muchos grandes que quieren

13. capturarme muerto o vivo.

[III] 14. Dicen que me andan buscando

15. pues sobra que me lo digan.

16. Si me sigue la justicia

17. yo combato a la guerrilla.

18. No me preocupa que tantos

19. quieran quitarme la vida,

20. por mi Colombia adelante

21. sé que no es causa perdida.

[IV] 22. A nadie le como cuento

23. de eso sí estoy convencido.

24. Cuando estuve en Charrasqueras

25. ahí muchos fueron testigos

26. de cómo brincaban dos negros,

27. un paraco y un guerrillo.

28. Si Acacio tenía la fama

29. pues Tayson salió más fino.

[v] 30. No creas que yo vengo solo

31. te equivocaste, bandido.

32. La causa es por el pueblo

33. ayudando al campesino

34. a que trabaje la tierra

35. y no le quiten sus hijos.

El cantor narra la historia en primera persona del singular, emplea el yo como sujeto de enunciación. Recuérdese el poema El gaucho Martín Fierro (1872), de José Hernández, en su segunda estrofa: "Pido a los Santos del Cielo / Que ayuden mi pensamiento; / Les pido 
en este momento / Que voy a cantar mi historia / Me refresquen la memoria / Y aclaren mi entendimiento" (Hernández, 2001, p. 99; énfasis nuestro). El canto es una biografía, una historia de vida. En el poema gauchesco referido, la identidad del cantor (narrador) y la del personaje de la historia son la misma. El yo, en este caso, es una unidad compuesta de esas dos identidades. En el corrido la identidad del personaje se desplaza y simbólicamente ocupa el lugar del cantor. El cantante presta su voz al personaje. El corrido cantado en primera persona es una puesta en escena, en la que el intérprete, como todo artista, encarna e interpreta, musicalmente, a su personaje: "Me apodan El Negro Tayson / es como me han conocido" (II, 8-9). El personaje no es de ficción, es una persona real que fungió como paramilitar. Así lo corroboró un desmovilizado del Bloque Tolima de las AUC en una entrevista en el marco de los Acuerdos de la Verdad: "Tayson, ese berraco era un negro malo. Como sería que, en los entrenamientos, cuando lo ponían a uno a voltear por todo eso, una vez nos cogió y eran ráfagas. Esos eran entrenamientos muy duros [...] Ese como que era del Urabá" (Cfr. Centro Nacional de Memoria Histórica, 2017, p. 128). Esta declaración sirve para examinar al menos dos aspectos fundamentales del corrido: la voz testimonial (texto histórico) y el héroe (texto artístico).

Este recurso narrativo de un yo que canta le confiere cierto efecto de veracidad por cuanto evoca una voz autobiográfica, que, al ser canción, se entiende, es una reelaboración artística y convierte a la persona en personaje. El corrido es, entonces, una narración que conjuga en su texto al Negro Tayson real y al Negro Tayson personaje en una sola identidad textual. El personaje de la canción adopta gran parte de la biografía de la persona real para posicionarse en el corrido como héroe en clave de un guerrero sobresaliente, destacado en la organización paramilitar por "bueno" (I, 3). La semántica de la palabra "bueno" no remite a bondad, en sentido religioso o moral. Ante todo, "bueno", definido en el contexto narrativo del propio corrido, significa bravura o temeridad. En este momento, se conjugan dos rasgos definitorios del personaje principal de los corridos prohibidos, a saber: la valentía, valor por antonomasia del héroe (Valbuena, 2007, p. 226) y el doble carácter 
de luz y oscuridad, de monstruosidad y heroicidad afirmativa (Valbuena, 2007, p. 233). La estrofa IV es un episodio completo, que inicia (v. 22) y cierra (v. 29) con su hombría. Los versos intermedios son la escena de sus desafíos que darían prueba del porqué no puede revelar su verdadero nombre (II, 10) y la causa de sus muchos enemigos (II). La estrofa III aporta el sentido de la palabra "bueno", que resulta ser axiológico y, por último, ideológico. Su hombría está en función de un ideal de patria (III, 20), por el que vale el sacrificio de ser perseguido por las autoridades.

Paradójicamente, cuenta el corrido, el Negro Tayson ayuda a construir patria combatiendo al enemigo que tiene en común con la nación: el guerrillero (III, 17). Y a pesar de ello, es un prófugo de la ley (II, 12-13; III, 16). Resulta ser un bandido, pero no en la connotación heredada del período de la violencia bipartidista, como aquellos guerrilleros liberales descritos en el "cancionero infame" y sobre quienes se evocan acciones calificadas como ruindades de hombres viles o hazañas gloriosas de héroes populares (Mora, 1998). El Negro Tayson es un outlaw o rebelde en el sentido de un bandido social perseguido por el Estado por su condición de criminal. Este sigue conviviendo con el campesinado por quienes es visto como un héroe (Hobsbawm, 1981, p. 17). El corrido no despeja la procedencia original de Tayson, no se sabe si es de origen campesino y tampoco si las comunidades -léase el pueblolo perciben como uno de los suyos. El yo narrador, por su parte, sí lo ubica del lado del campesinado: "ayudando al campesino" (v, 33). Esta indeterminación es suplida en el corrido de la pista 7 al sostener que "Con el apoyo de todos los campesinos / y por ser bueno me quiere / todo el pueblo". Se percibe aquí una comunión entre el pueblo y el paramilitar, según el corrido es su deseo que en la tumba se ponga: "el Comando del Pueblo". No obstante, tal comunión nunca es declarada por un personaje campesino, puesto que no se refrenda ese ideal desde este sujeto cultural.

La narrativa que traza este corrido resalta la teleología social, sobre la que se sustenta su axiología, del bien común del pueblo. Dada esa alta misión de un pueblo libre -de guerrilleros, se entiende (III, 17; v, 31)-, se explica la gesta épica de Tayson: "por mi Colombia adelante 
I sé que no es causa perdida" (III, 20-21) y "la causa es por el pueblo" (v, 32). Sin embargo, la causa paramilitar no es revolucionar un orden percibido como degradado. Su orilla ideológica de ultraderecha los motiva a luchar por un viejo orden, según ellos, el correcto, que la insurgencia de izquierda ha atentado y deteriorado. Como el fenómeno guerrillero se propagó por una parte considerable del país, el paramilitarismo requería una rápida extensión. Esto lo consigna el corrido al señalar una geografía nacional con un punto de partida: Urabá (I, 2), y uno de llegada: el Guaviare (I, 7). Recuérdese que antes de revelarse la identidad del personaje del corrido, se anuncia su procedencia y valía: "Yo vengo del Urabá / me trasladaron por bueno" (I, 2-3). Comunicar el lugar de procedencia es tan importante que resulta ser motivo de orgullo, por eso antes de la primera estrofa, que inicia con la voz narrativa afincada en yo, el corrido suelta una arenga: " $i Y$ por el Urabá!”. Con los dos primeros versos, el corrido inicia su relato con la fusión identitaria de la persona y el lugar: "yo" refiere al Negro Tayson, cuyo origen heroico se remonta a la región del Urabá.

En términos de la composición narratológica del corrido, el narrador de las proezas es el mismo guerrero. En el juego de superposición de voces, el yo cantor del corrido es el guerrero. La ficción de un guerrero cantor es fundamental para hacer conciencia de que el corrido está contado desde la posición del victimario paramilitar. Su función dentro del conflicto armado en el Guaviare es básicamente expulsar a los guerrilleros de la región. No se menciona nada acerca de intereses sobre controlar las plantaciones de coca, dominar los corredores de transporte de insumos para la producción de cocaína y llevarla a los puntos de acopio. La causa parece noble: se lucha por el pueblo, para liberarlo del yugo guerrillero. Esta es la narrativa con la que se desenvuelve el corrido. Es su teleología (v). A la guerrilla se le acusa (por inferencia textual) de cooptar la fuerza laboral campesina en dos direcciones: tierra e hijos (v, 3435). El campesino, según la versión cantada de Tayson, no es libre para trabajar la tierra y sus hijos son sustraídos del seno familiar para ser reclutados en los frentes guerrilleros. Al plantearlo así, y por oposición a su enemigo, se entiende que el paramilitar no practica ninguno de esos abusos. 
Para que Colombia salga adelante (III, 20), se debe liberar a los campesinos de la opresión guerrillera. Así se canta en otros corridos: "guerrilla maldita / que a mi pueblo hace masacres" en el Guaviare (pista 3) y "quiero mirar mi país libre de todo / de los Buitrago / y malditos guerrilleros", afirma el comando Colacho (pista 7). "Todo", en estos versos, no es un conjunto universal. Está restringido a los Buitrago y los guerrilleros. El paramilitar, por este conducto narrativo, es un vengador del campesino. Sin embargo, los informes del Centro Nacional de Memoria Histórica (CNMH) recopilan evidencia de que el actuar del paramilitarismo corresponde a una máquina sanguinaria sin refreno. Esto es de vital importancia porque, según Hobsbawm (1981), la moderación es un rasgo esencial de la imagen y entendimiento de lo que es el bandidaje social. Si el paramilitarismo se apropia y profesa, por medio de los corridos, un sentido de la justicia, esta visión de lo correcto termina siendo aceptada por el campesino por uso de la fuerza y el terror. En tal dirección, al vengador se le percibe como héroe, no a pesar del miedo y el horror de sus actos, sino a causa de estos (Hobsbawm, 1981, p. 58).

El corrido, de manera consciente o no, sigue una convención ampliamente desarrollada en la literatura gauchesca y el desafío como prueba de la bravura del héroe que muchas veces viene precedida de fama. El desafío es un acto ritualizado de forma oral, que en el caso de la gauchesca es constitutivo de ese género literario (Ludmer, 2000); la lógica del desafío también es central a las historias de bravos de Borges (Dabove, 2006). La fama de bravo no tiene fundamento si no se comprueba con la confrontación y si no deja una anécdota que ayude a propagar la leyenda. Esta información de la literatura gauchesca puede servir de clave para analizar los corridos. Por ejemplo, en el corrido de la pista 3 se tienen los siguientes versos sobre la bravura: "no soy un cobarde / soy hombre entre los hombres / y no me le humillo a nadie", y termina con un desafío a la cúpula de las Farc: "al Mono y al Tiro Fijo los reto, par de cobardes". En el corrido estudiado, hay un duelo épico y brincan dos negros: un guerrillo y un paraco (IV, 26-27). El negro paraco es Tayson y el negro guerrillo es Acacio (IV, 28). Acacio no solo es el opuesto ideológico -su enemigo-, es su antagonista dramático. El afamado bravo a quien hay que 
desafiar y vencer. El combate contra el Negro Acacio es el gran reto que debe superar Tayson, para constatar quién es el más guapo:

Si Acacio tenía la fama

pues Tayson salió más fino (Iv, 28-29).

\section{¿Por qué "Acacio tenía la fama"? El "amo y señor de la coca"}

El Negro Acacio es el contendiente contra quien el héroe del corrido debe demostrar su "finura", nombre popular de la valentía como rasgo representativo del héroe en este género musical (Valbuena, 2007, p. 226) y también del código personal desde el cual se juega la vida misma (2007, p. 230). Esta, una vez demostrada, merece ser acreditada como verídica para ser recontada por "muchos testigos" (IV, 25). Esta prueba de hombría y bravura recuerda que, en la literatura de Borges sobre guapos, por ejemplo, en el cuento "Hombre de la esquina rosada", la fama es un relato que antecede al guerrero consolidado y se convierte en el objeto del deseo del nuevo héroe. Solo con quien tiene acaudalada fama vale la pena el duelo:

Yo soy Francisco Real, un hombre del Norte. Yo soy Francisco Real, que le dicen el Corralero. Yo les he consentido a estos infelices que me alzaran la mano, porque lo que estoy buscando es un hombre. Andan por ahí unos bolaceros diciendo que en estos andurriales hay uno que tiene mentas de cuchillero, y de malo, y que le dicen el Pegador. Quiero encontrarlo pa que me enseñe a mí, que soy naides, lo que es un hombre de coraje y de vista (Borges, 1974, p. 331).

En el corrido de la pista 10, el protagonista en apariencia logró vencer a su rival, pero el antagonista también resulta ser el personaje principal de otro corrido. Se trata de Alias El Negro Acacio, compuesto por Rafael Medrano y Alirio Castillo (2016), interpretado por El Halcón de Durango e incluido como la pista 7 del Volumen 16 de la Colección Corridos Prohibidos. Con las mismas convenciones empleadas anteriormente, se transcribe este corrido: 
[I] 1. A orillas del río Guaviare

2. allá por Barranco Minas

3. se escuchaban los motores

4. surcaban aquel espacio

5. eran los Super Tucanos

6. buscaban al Negro Acacio.

[I] 7. Tomás Medina Caracas

8. le decían El Negro Acacio

9. amo y señor de la coca

10. y del Frente Dieciséis.

11. Nadie pasaba ni entraba

12. si al Negro no mencionaba.

[III] 13. Más del ochenta por ciento

14. de la coca controlaba

15. y no solo del Guaviare

16. al norte, al sur y demás

17. nadie compraba una libra

18. sin consultarle a Tomás.

[Iv] 19. Era la registradora

20. de aquel frente de las Farc.

21. Toda la base de coca

22. tenía que llegar con él

23. tenía retenes sembrados

24. dentro, fuera y por doquier.

[v] 25. Ándele parce, hágale, hágale

26. Pícale que es de la gente del Negro Acacio.

27. Y este es El Halcón de Durango. 
[vi] 28. Dijo un viejo traficante

29. cuando lleguen a un retén

30. si quieres volver seguro

31. y te concedan el paso

32. diles que eres de la gente

33. que trabaja con Acacio.

[vII] 34. Un día llegó Fernandinho

35. y le propuso tratar

36. le dijo que le vendía

37. de rifles un arsenal

38. y de ahí se abastecía

39. la guerrilla de las Farc.

[VIII] 40. A las cuatro treinta y nueve

41. le cayeron los Tucanos

42. haciendo grandes destrozos

43. en todo su campamento

44. ahí cayó El Negro Acacio

45. aunque no hallaron su cuerpo.

[Ix] 46. Por ahí dicen que El Cepillo

47. que en verdad era muy fiel

48. ya muerto arrastró su cuerpo

49. pa' que no dieran con él

50. y no se dieran el gusto

51. de llevárselo al cuartel.

Este corrido está muy bien estructurado con estrofas de seis versos. Excepto la v, que tiene tres, y sirve como intermedio justo a la mitad de la canción. Introduce la voz del grupo musical El Halcón de Durango (v, 27). El cantor es la agrupación y se rompe la unidad que presentaba el corrido sobre el Negro Tayson, entre el personaje y el intérprete. El corrido sobre el Negro Acacio es cantado en tercera 
persona. Eso no es una anomalía, necesariamente, del género, es una consistencia con su propio relato, pues las dos últimas estrofas cantan su muerte.

La heroicidad del Negro Acacio se establece por la persecución que hace el gobierno con aviones Super Tucano. La locación es Barranco Minas (I, 2), a esa altura el río Guaviare sirve de límite natural entre los departamentos de Guainía y Vichada. El río ha sido escenario de sangrientas disputas por su posición estratégica como corredor para el transporte de insumos químicos para los laboratorios clandestinos y para mover cocaína. Desde Barranco Minas, siguiendo el cauce del río Guaviare hacia el occidente, se llega en este orden a Caño Jabón y Mapiripán. Poco antes de llegar a este último, se encuentra Charras, desde donde se embarcaron los paramilitares para ejecutar la masacre en julio de 1997. El serpenteante cauce del río Guaviare recorre locaciones que fueron disputadas entre los mismos paramilitares "Martín Llanos" y Miguel Arroyave, pero también fue el escenario de oscuras alianzas entre este último y el Negro Acacio para el usufructo ilegal de una pista aérea clandestina (Sierra, 2004).

De su actividad insurgente, convicción ideológica o proyecto de país, el corrido no dice nada. El Negro Acacio, personaje de esta tonada, es narcotraficante y únicamente eso: "amo y señor de la coca" (II, 9). En consecuencia, la narrativa que traza el corrido es que la Fuerza Aérea Colombiana lo persigue por narcotraficante y no tanto por guerrillero. De la opresión o liberación del pueblo, temas centrales en los corridos prohibidos paramilitares, no se dice nada en este narcocorrido guerrillero. Las estrofas II y III cantan la heroicidad del personaje, que se fundamenta en ser la máxima autoridad de la región y del Frente 16 de las Farc (II, 10). Su nombre es un salvoconducto para moverse en su zona de influencia y, por lo mismo, este corrido celebra la identidad del Negro Acacio revelando su nombre verdadero: Tomás Medina Caracas (II, 7).

Revelar la identidad del héroe no es solo un dato de información que aporta el corrido, es una celebración porque las estrofas II y III conforman una unidad narrativa sobre el personaje que abre (II, 7) y cierra (III, 18) con su nombre. No es simplemente un hombre 
poderoso, bien sea por fuerza de la violencia o por influencia del dinero, su nombre y alias son el sello doble de la más grande autoridad. Si el tema de las estrofas fuera el poder, bastaría con aquellas dos. Dado que se canta su autoridad, esta se extiende por las estrofas IV y VI. Además, las estrofas III y IV componen otra unidad: la autoridad representada en la centralidad. El lugar, el Guaviare, y la persona, Acacio, son el centro gravitacional alrededor del cual gira este universo narrativo. La autoridad de la persona se extiende allende del Guaviare, al norte y al sur (III, 16). Las coordenadas septentrional y austral se toman en relación con el Guaviare, es decir, este es el centro. Toda la producción de base de coca debe pasar por él, como si fuera la única registradora (IV, 19). La única autorizada o, mejor aún, es como una registradora mítica con la facultad de estar en todas partes (IV, 23-24). Registradora o retenes son una suerte de presencia ubicua de Acacio. El último verso de la estrofa VI cierra esta gran unidad temática de nuevo con su nombre de guerra (vi, 33), lo que da razón al título del corrido: Alias El Negro Acacio.

Para un corrido de ocho estrofas (la $\mathrm{V}$ es una falsa o media estrofa, que establece un hiato en la historia), resulta que el tema de la autoridad toma la mitad de su extensión. Debe ser así porque el corrido crea una simbología alrededor de la figura del Negro Acacio. Su radio de influencia es una suerte de Guaviare mitológico: circular y cerrado, cuyo eje central, en el espacio geométrico, es Acacio. El corrido se aleja de la representación mimética del combatiente y por tanto renuncia a cualquier compromiso con la verosimilitud histórica. Es una construcción poética del orden mítico: ese mundo fabuloso está colmado por la presencia poderosa. Su autoridad llena cada rincón. El lugar y la persona conforman una unidad indiscernible. La distinción de una mímesis reflectante de la realidad, gesto de interés histórico, con respecto a una creación poética está en la oposición misma que plantea Aristóteles (1988) entre los historiadores y los poetas, en el capítulo Ix de la Poética. La consecuencia de tal separación aristotélica, en el corrido, es crear una simbiosis que opera en un principio de identidad: no existe, en este universo narrativo del corrido, Guaviare sin Acacio, ni viceversa. 
La estrofa VII es una unidad breve y autónoma. Es una suerte de célula que condensa una porción de información muy importante sobre la narcoeconomía como una fuente de financiación de la guerrilla. Con la coca, el Negro Acacio paga las armas de su Frente. La canción quizás sin saberlo hace una sinécdoque y en lugar de referirse al Frente Dieciséis, lo toma como la totalidad de la guerrilla fariana: "y de ahí se abastecía / la guerrilla de las Farc" (vII, 38-39). No obstante, ni la estrofa ni el corrido hacen una sola mención a los propósitos revolucionarios para los que se adquieren esas armas. El arsenal está desideologizado y solo tiene un valor relativo en tanto se adquiere con los dineros del tráfico de drogas y por la existencia de otro mercado ilegal: el del tráfico de armas, por intermedio de Fernandinho (VII, 34). Otro alias, significativamente extranjero, que evidencia la relación entre el narcotráfico internacional y la guerrilla por intermedio del Negro Acacio (Semana, 2001a; 2001b).

Después de este hiato, el universo narrativo vuelve a su simbología mítica. Los aviones Tucano del inicio reaparecen al final; esto sirve como índice de apertura y conclusión, confiriéndole redondez y cerrazón al entramado del relato. Si se acepta la hipótesis de que los aviones reaparecen en la tarde (VIII, 40) del mismo día (I), se obtiene una especie de tiempo dilatado, suspendido o presente eterno. Los Tucano de la primera estrofa funcionan como las aves negras agoreras del romanticismo europeo para anunciar la muerte del héroe. En este caso no solo la anuncian, ellas mismas son la muerte para el héroe. El cuerpo de Acacio desaparece (viII, 45). Se dice que "Cepillo" privó del trofeo a los ganadores, que no son los guerrilleros. El corrido termina con un rumor (IX, 46). La no confirmación del dato es equivalente de la sustracción del evento del fluir histórico para instalarlo por fuera del logos, esto es, en la tradición oral. El bombardeo es un dato cierto, no así el destino del cuerpo de Acacio. Por la indeterminación con que concluye la última estrofa, el corrido inscribe la historia de Tomás Medina Caracas, alias El Negro Acacio, en la fábula.

Este corrido ofrece dos dimensiones textuales importantes para considerar la construcción de una memoria histórica. La primera atiende al contenido o referente: Tomás Medina fue un guerrillero narcotraficante. La segunda dimensión atañe a la forma o modo de 
la representación: la canción se enraíza con el mito. De esta manera, las claves míticas o ancestrales contenidas en el relato pueden ofrecer rutas no solo para (re)contar el conflicto armado, sino para comprenderlo. Por lo mismo, el género del corrido es una memoria en el contenido y en la forma. En el contenido remite a la memoria histórica. En la forma, brinda una narrativa para registrar y trasmitir el multivalente conflicto en el Guaviare. En últimas, descubrir claves míticas no asemeja el relato del corrido a la falsación histórica. Al contrario, revela la complejidad épica del conflicto.

El Guaviare en el relato del corrido funciona como un microuniverso narrativo que contiene claves para entender e iluminar el conflicto armado a escala nacional. Por eso, en semejanza con el género gauchesco, desde el cual se puede elaborar un tratado sobre la patria, porque ha cifrado literariamente su constitución (Ludmer, 2000), se considera que el corrido también ofrece esa oportunidad:

De combate en combate, de rebelión en rebelión, no ha dejado de surgir en ningún momento del pasado siglo [xIx] el corrido oportuno que señale la parte épica de los combates, las proezas de los ejércitos, las hazañas de los valientes; lo mismo que el temerario desdén con que afrontan la muerte numerosos cabecillas rebeldes a todos los gobiernos, bandidos que han sido antes soldados, u hombres de campo que han sabido conservar una absoluta independencia de acción en contra de las leyes (Mendoza, 1997, p. 132).

\section{El escenario de la guerra entre los "dos negros, un paraco y un guerrillo"}

Los dos protagonistas de los corridos representan los extremos opuestos de los actores armados ilegales en Colombia. En el Guaviare, la guerrilla históricamente había hecho presencia y el paramilitarismo llegó para disputarle el territorio. Sin embargo, la historia reciente de la región está marcada por la coca y el conflicto: dado que cuando los colonos campesinos provenientes de otras zonas del país se adaptaron a las condiciones del entorno selvático y, en especial, a las actividades productivas en torno a los cultivos de uso ilícito, primero marihuana y después coca, esta se entendió como la única alternativa económica (Unigarro, 2020). En este contexto, 
la guerrilla de las Farc funciona en la zona "más o menos desde el 76 [por medio] de grupos pequeños de tres o cuatro [milicianos] que pasaban o dejaban mensajes" (entrevista colectiva, octubre de 2019). Como organización armada de ideología comunista con el discurso de proteger a los campesinos y poner orden en el territorio, se la reconoce desde inicios de la década de 1980, cuando se establece por todo el Guaviare desde el río Guayabero hasta el centro poblado de Charras, donde según sus pobladores se vieron los guerrilleros por primera vez en 1984 (Gómez, 2017, p. 86).

Desde esta década, dada la nula presencia estatal, en la medida en que se extendieron los cultivos de coca por los ríos Ariari, Guayabero y Guaviare, las Farc buscaron capitalizar algunos procesos de colonización mediante la creación y consolidación de los frentes 1,7 , 16, 39 y 44, los cuales históricamente mantuvieron un férreo control social en el territorio (González, 2007, p. 250; Verdad Abierta, 2016). Así, este grupo armado ilegal no solo extendió su capacidad operativa y militar en la región, sino que se encargó de la provisión de armas, dinero y combatientes para los otros frentes del país (Defensoría del Pueblo, 2019). Esto desató la reacción de los paramilitares para contrarrestar el alcance de la guerrilla:

En la Tercera Cumbre Nacional del Movimiento de Autodefensas Campesinas de Urabá y Córdoba, celebrada en noviembre de 1996, las autodefensas anunciaron la recuperación de territorios en los Llanos Orientales, y sus intenciones de entrar a confrontar a la guerrilla en sus propias regiones de Guaviare, el Caquetá y el Putumayo. [...] Este anuncio estuvo precedido de numerosas incursiones paramilitares realizadas en y desde San José del Guaviare durante el mismo año, y hacia las zonas aledañas a los municipios de San José y El Retorno. [...] De hecho, meses antes, cuenta el propio Castaño que se había reunido con los cocaleros de Guaviare y del Caquetá en La Cooperativa, departamento del Guaviare, en busca de apoyo financiero para sus incursiones en el sur del país. Algunas de estas incursiones fueron las que se realizaron en la cuenca del río Guaviare, en las áreas de Mapiripán y Puerto Alvira (González, 2007, pp. 252-253).

De esta forma, en el territorio guaviarense se involucraron múltiples actores como las Autodefensas Campesinas de Casanare (ACC) y el Bloque Centauros de las AUC proveniente del Urabá, 
con el fin de disputarle el control y las finanzas a los frentes 1,7 y 44 de la guerrilla (El Espectador, 2020; Verdad Abierta, 2018). El hecho que marcó la llegada de "los paras" fue la masacre de Mapiripán en julio de 1997, cuando desde la Casa Castaño se enviaron hombres del Urabá que aterrizaron en el aeropuerto de San José, se desplazaron por la Trocha Ganadera hasta el centro poblado de Charras donde reunieron a los habitantes -quienes los confundieron con soldados por su aspecto y uniforme- y se presentaron como Autodefensas Campesinas de Córdoba y Urabá (ACCU) (Verdad Abierta, 2016). Desde Charras, se desplegó el operativo fluvial hacia Mapiripán, donde la incursión paramilitar que duró del 15 al 21 de julio ocasionó una de las más cruentas masacres del conflicto armado en el país (Gómez, 2017, p. 88; Verdad Abierta, 2018).

Esta masacre fue la primera de una serie de hechos victimizantes que aterrorizaron a la población, y sirvió como antecedente para obligar al cumplimiento de las exigencias paramilitares. A pesar de ser quienes supuestamente acabarían con las acciones de la guerrilla, estos actuaron peor al perpetrar todo tipo de actos violentos en contra de la población rural, que terminó obligada a pagar impuestos y sometida ante ambos bandos. Un hecho semejante fue la masacre de Caño Jabón, un caserío sobre el río Guaviare en el municipio de Mapiripán, ocurrida el 4 de mayo de 1998. Esta se atribuyó a las ACCU y se condenó por homicidio agravado, terrorismo y concierto para delinquir a cuatro paramilitares, entre ellos al protagonista del corrido de la pista 10: alias Tayson (Fiscalía General de la Nación, 2012). El personaje real se incorporó a las AUC en 1997, después de pertenecer al grupo guerrillero Ejército Popular de Liberación (EPL), y el mismo año fue trasladado al Guaviare donde recibió una escuadra con 17 hombres y participó como comandante en la operación Caño Blanco ocurrida el 23 de noviembre (Valencia, 2015, p. 3).

La consolidación de las ACCU en la región dio origen a su redenominación como Bloque Centauros de las AUC, el cual siguió causando terror con sus incursiones armadas en veredas como Guanapalo, Caño Makú, Charrasquera, muy cercanas a Charras, durante los años 2002 y 2003, en las que el personaje del corrido también participó: 
La Fiscalía manifestó que los hechos reconocidos por el postulado son el homicidio de una mujer de aproximadamente 20 años, ocurrido en la primera mitad del año 2002, en el municipio [sic] de Charrasquera de San José del Guaviare y la masacre ocurrida entre el año 2002 y 2003, en la vereda el Trin en San José del Guaviare, donde les dieron una lista con $7 \mathrm{u}$ 8 personas, que fueron retenidas y asesinadas (Valencia, 2015, p. 4).

El corrido anónimo retorna y aquel "Cuando estuve en Charrasqueras" [Iv, 24] toma el carácter de confesión. En el relato del corrido, la vereda Charrasquera es el escenario del duelo entre dos negros: los dos exponentes más importantes de la guerrilla y el paramilitarismo de la región. La heroicidad del Negro Tayson queda definida no solo por su hombría al ser capaz de enfrentar y vencer al Negro Acacio. El corrido hace mucho más que eso, de lo contrario reduciría el conflicto interno a su componente armado. Para el corrido es central dejar claro que Acacio es un antagonista ideológico por su afiliación guerrillera. Igualmente, la memoria que le interesa consignar y trasmitir al corrido es la de un proyecto de nación, expresado en los descriptores patria, pueblo, campesino, mi Colombia y, ante todo, el haber sido comisionado por la sede natural de las AUC en el Urabá para combatir a la guerrilla en el Guaviare. Su más alta bandera heroica es expandir el proyecto paramilitar y aniquilar a la guerrilla opresora del pueblo. No obstante, al confrontar no solo a los personajes de los corridos, sino reconstruir los hechos del conflicto armado con una perspectiva microrregional y local, el proyecto ideológico que se pretende transmitir se desmorona y adquiere carácter mítico.

En lugar de ayudar al campesino para que trabaje la tierra y no le quiten sus hijos pues la causa es por el pueblo (v, 32-35), las acciones paramilitares en la región evidencian lo contrario. Si bien la vereda Charrasquera es mostrada en el corrido como el gran escenario donde la hombría y fama del bravo negro es expuesta en la escena de confrontación sangrienta entre grupos guerrilleros y paramilitares (IV), la realidad es que la población en efecto fue victimizada y el caserío destruido. Este concentraba aproximadamente treinta construcciones hasta que fue tomado el 31 de octubre de 2002 por las Farc, tras ser ocupado por los paramilitares en septiembre: 
La guerrilla se agarró con los paras, estábamos celebrando el día de los brujitos, nos llevaron para la cancha, nos dijeron que nos quedáramos todos ahí [...] Cuando esos paracos nos hicieron señas [...] tumbamos una cerca de alambre que había, nos pasamos y nosotros que salimos y una bomba que cae ahí, si hubiéramos estado todo ese gentío nos hubiera matado en la cancha (Entrevista personal, marzo de 2019).

Este es el hecho victimizante que marcó la historia de la vereda. Se entiende como el significado real de "el conflicto" para los habitantes cuando solo utilizan la palabra con el artículo masculino precedente para hacer referencia al hecho que implicó el abandono del lugar y la ruptura de sus formas de vida (Unigarro, 2020, p. 190). El corrido, al localizar el encuentro épico entre los dos negros en la vereda, tiene el efecto de darle relevancia y trascendencia, por lo que el lugar adquiere no solo rememoración, sino que provoca interés. El hecho ha sido narrado en distintas fuentes:

Los guerreros quemaron Charrasquera, donde no quedó ni una casa. Hay tantas historias sobre la manera en que ocurrieron las cosas, que uno no sabe si son verdades o si forman parte de las historias de terror que se cuentan antes de que haya muertos en la guerra (Ardila, 2004, p. 138).

En 2002, los enfrentamientos entre las AUC y las Farc en Puerto Ospina y Charrasquera (hoy denominado "Pueblo Quemado") dejaron claro el avance territorial de las AUC (Mahecha y Franky, 2011, p. 208).

[...] La segunda arremetida fue en 2003, bajo el mando de Pedro Oliverio Guerrero, alias Cuchillo, cuando los enfrentamientos entre paramilitares, Ejército y Farc provocaron el éxodo total de los habitantes de Charrasqueras, hoy conocido como "el pueblo quemado" por la guerra (Bolaños, 2017, párr. 20).

Esa guerra fue muy terrible, yo recuerdo los enfrentamientos de la vereda Charrasquera en el 2002, allí no quedó nadie, la gente toda se desplazó, hasta el caserío lo quemaron (don Luis, citado en Gómez, 2017, p. 90).

Esto muestra que para los habitantes del Guaviare la guerra hizo parte de su cotidianidad y que tanto los enfrentamientos como las acciones victimizantes permanecen vivas en las historias, de transmisión oral, entre los lugareños. Sus historias consignan y 
destacan ese elemento terrorífico que articula sus textos orales, como se registra en los fragmentos citados (Ardila, 2004, p. 138; Gómez, 2017, p. 90). De hecho, eso es notorio cuando los habitantes de Charrasquera llaman "el conflicto" a la toma y destrucción de su vereda. Los testimonios apelan a los episodios de terror porque este funciona como el "lance patético" que da unidad de acción al relato (Aristóteles, 1988, p. 166). El páthos aristotélico busca transmitir o provocar una pasión en el espectador, bien sea de temor (phóbos) o de compasión (éleos). Sus testimonios despiertan temor por los guerreros paramilitares o guerrilleros y compasión por las víctimas. Por ejemplo, el personaje de la pista 10 siguió delinquiendo en la zona. Se dice que en el año 2003 le apuntó con un fusil a una mujer a la que señaló como "enfermera de la guerrilla" en Charras, solicitante en un proceso de restitución en el que se alude a los alias de Tyson como paramilitar y El Negro Acacio como guerrillero, respectivamente (Ramírez, 2017).

De cualquier forma, las veredas Charras y Charrasquera, con o sin personajes, fueron el escenario de la intensa actividad paramilitar, lo que ocasionó el desplazamiento de la totalidad de sus comunidades. Permanecieron deshabitadas por algunos años hasta el retorno voluntario de algunas familias que hoy son sujeto de reparación colectiva al ser desplazadas por grupos armados al margen de la ley (Unidad para la Atención y Reparación Integral a las Víctimas, 2017). Al cabo, alias El Negro Acacio, el además mítico "guerrillero inmortal" por cuenta de una historia también mítica, terminó bombardeado en el Guaviare tras ser la caja registradora de las Farc al manejar el negocio del narcotráfico en otros departamentos como Vichada y Guainía (El Tiempo, 2007). El Negro Tayson se desmovilizó colectivamente en el 2006 con el Bloque Héroes del Llano y del Guaviare, pero fue excluido del proceso de Justicia y Paz años después (Valencia, 2015).

\section{A modo de conclusión: la memoria del conflicto en los corridos prohibidos}

El conflicto armado colombiano ha sido eje central de la música popular. Las canciones de guerrilleros y bandoleros que tuvieron 
alguna circulación local y regional desde la década de 1950, por cuenta de la dinámica de las tradiciones orales primarias, pueden considerarse los antecedentes de los corridos prohibidos no solo porque exaltaban a personajes caracterizados como héroes o villanos, sino que también fueron menospreciadas por la radio y la industria discográfica dada su inconveniencia política (Mora, 1998, p. 33). La pervivencia de esta invisibilidad dificulta entender que, en cuanto expresión musical y narrativa, los corridos representan a la sociedad que los origina y reproduce, pueden contribuir en la construcción del sentido de prácticas sociales contrahegemónicas y, especialmente, fortalecer la capacidad de recordar o, por lo menos, traer al presente algunos hechos del pasado que no son ni pueden ser monopolio de la historiografía (Almonacid, 2016a, p. 70).

Si bien se abordaron dos corridos cuya pretensión era el reconocimiento de los protagonistas mediante la legitimación/deslegitimación de sus vidas problemáticas, con narraciones detalladas de actos violentos o delictivos para modificar la representación social en relación con el prestigio o la autoridad de los sujetos en cuestión (De la Garza, 2016, p. 24), lo que se escucha permite hacerse una idea más allá de las experiencias personales y adentrarse en las realidades violentas de un contexto territorial con condiciones políticas, económicas y sociales específicas, a pesar de que algunos acontecimientos narrados solo tengan información de prensa como fuente. Este parece ser el caso del corrido cuyo protagonista es el comandante guerrillero, de quien solo se refieren hechos de conocimiento público. Por el contrario, el corrido del que se desconoce su autor e intérprete, tiene un trasfondo ideológico que se intenta justificar, plantea una narración factual de la trayectoria vital del personaje y, además, revela un hecho que, sin que se pueda comprobar su veracidad, invita, motiva y provoca la indagación. De ahí la performatividad de este corrido prohibido.

Se desconocen las fuentes. Se ignora el público al que estaba destinado. Sin embargo, no fue coincidencia encontrarlo en el mismo lugar. Se tenía idea de Charrasquera, del hecho victimizante que allí ocurrió y lo traumático que fue para su gente, pero encontrar otra fuente permitió indagar sobre la narración, la memoria, para 
descubrir discursos a veces complementarios y otros contradictorios que, más que cuestionar su validez o veracidad, permitieron entender que no existe una sola y única verdad, puesto que cada uno produce una narración desde su propia subjetividad. Los corridos, aunque tienen pretensión de verdad histórica, no cuentan verdades, sino perspectivas, lo que puede tener mucho valor para una sociedad que no está dispuesta a escuchar opiniones que de antemano no comparte, pero que permiten ver de qué está hecho el país (De la Garza, 2016, p. 59).

Los corridos prohibidos no son los relatos verídicos del conflicto armado colombiano ni de la violencia asociada a este, solo son otras versiones que pueden contribuir a la construcción de la memoria del conflicto como punto de partida fundamental para reconocer los hechos violentos del pasado con el propósito de dejarlos atrás y superarlos, sin que se olviden. Esto tiene un gran potencial de reparación y transformación que emerge como posibilidad de resistencia y resiliencia de los individuos y las comunidades frente a la lógica del conflicto. En definitiva, los corridos prohibidos pueden aportar en la construcción del sentido histórico y la gestación de paz territorial en la medida en que brindan memorias sociales alternativas (Almonacid y Burgos, 2018). Esto es indispensable en regiones que, como el Guaviare, tienen realidades locales que requieren de una comprensión particular por cuenta de dinámicas territoriales complejas y problemáticas. De ahí que tenga sentido promover la construcción de una memoria del conflicto en cada lugar, especialmente en aquellos afectados por la guerra y la violencia, donde sus habitantes han generado arraigo en su territorio a pesar de las adversidades 【 


\section{Referencias}

Almonacid, J. A. (2016a). Balas, narcotráfico y "corridos prohibidos": la banda sonora del conflicto colombiano. Mitologías hoy, (14), 57-73. http://dx.doi.org/10.5565/rev/mitologias.370.

Almonacid, J. A. (2016b). Cantar y contar historias: las funciones sociales del corrido prohibido en Colombia, otras formas de enseñanza. [Tesis de Maestría, Universidad Michoacana de San Nicolás de Hidalgo, Morelia, México].

Almonacid, J. A. y Burgos, C. J. (2018). Memoria y enseñanza de la historia del narcotráfico y las guerras esmeralderas: el valor sociocultural del corrido prohibido. Historia y Memoria, (17), 91-123. https://dx.doi. org/10.19053/20275137.n17.2018.7456

Ardila, G. (2004). El río Guaviare: espejo de Colombia. Procesos: Revista Ecuatoriana de Historia, (20), 133-140. https://repositorio.uasb.edu.ec/ bitstream/10644/1696/1/RP-20-TE-Ardilla.pdf

Aristóteles (1988). Poética (V. García Yebra, Trad.). Gredos.

Azuela, M. (1988). Los de abajo. AllCA XX.

Bal, M. (1997). Narratology. University of Toronto Press.

Betancourt, D. (1999). Memoria individual, memoria colectiva y memoria histórica: lo secreto y lo escondido en la narración y el recuerdo. Hojas Universitarias, (47), 17-22. http://editorial.ucentral.edu.co/ojs_uc/ index.php/hojasUniv/article/view/1386/1441

Bolaños, E. A. (2017, abril 12). A desenterrar los muertos de la guerra. El Espectador. https:/www.elespectador.com/colombia2020/territorio/ desenterrar-los-muertos-de-la-guerra-articulo-855344/

Borges, J. L. (1974). Hombre de la esquina rosada. En Obras completas 19231972 (pp. 329-334). Emecé.

Burgos Dávila, C. J. (2013). Narcocorridos: antecedentes de la tradición corridística y del narcotráfico en México. Studies in Latin American Popular Culture, (31), 157-183. https://dx.doi.org/10.7560/SLAPC3110.

Burgos Dávila, C. J. (2014). El quehacer etnográfico: experiencias y técnicas de investigación en el estudio del narcocorrido. En A. Mojardín, C. Zavala y B. Arita (Coords.), Nuevas rutas de investigación e intervención 
psicológicas (pp. 201-228). Universidad Autónoma de Sinaloa y Universidad Autónoma de Nayarit.

Castro Roa, D. P. (2018). Música en el tiempo y el silencio: narración del conflicto armado a través de la música popular. Amerika, (18). https://dx.doi.org/10.4000/amerika.9051

Centro Nacional de Memoria Histórica (2017). De los grupos precursores al Bloque Tolima (AUC). Informe No. 1. Centro Nacional de Memoria Histórica.

Como 'el guerrillero inmortal' era conocido el 'Negro Acacio', muerto en bombardeo en el Guaviare. (2007, septiembre 2). El Tiempo. https://bit.ly/2Pocup7

Dabove, J. P. (2006). Sobre algunas ficciones de violencia en la obra de J. L. Borges. Variaciones Borges, (22), 167-189.

Defensoría del Pueblo (2019, enero 15). Alerta Temprana No. 005-19. https:// bit.ly/2PpgC8h.

De la Garza, M. L. (2016). Los trabajos discursivos de los corridos chiapanecos. En Á. Ochoa (Comp.), Con el permiso de ustedes: Una historia muy corrida (pp. 23-64). El Colegio de Michoacán.

Equipo Humanitario Colombia (2013, diciembre 13). Colombia Informe Flash MIRA: Municipio San José del Guaviare - Vereda Charras (Guaviare). United Nations Office for the Coordination of Humanitarian Affairs. https://bit.ly/3wndZEs.

Fiscalía General de la Nación (2012, octubre 10). Condenado Salvatore Mancuso por masacre de Caño Jabón. https://www.fiscalia.gov.co/ colombia/noticias/condenado-salvatore-mancuso-por-masacrede-cano-jabon/

Friedmann, S. (2009). Del corrido al narcocorrido. En P. Vignolo (Ed.), Ciudadanías en escena: performance y derechos culturales (pp. 193-200). Universidad Nacional de Colombia.

García, F. (1995). Coca, guerrilla y sociedad civil en el Guaviare: regulación de conflictos y otros controles. Colombia Internacional, (29), 18-29. http://dx.doi.org/10.7440/colombiaint29.1995.02.

García Márquez, G. (2012). Los funerales de la Mamá Grande. Norma. 
Geertz, C. (1992). La interpretación de las culturas (A. L. Bixio, Trad.). Gedisa.

Genette, G. (1989). Palimpsestos: la literatura en segundo grado (C. Fernández Prieto, Trad.). Taurus.

Gómez, G. (2017). Un breve recorrido por la historia del departamento del Guaviare. Noche y Niebla, (56), 86-91. https://www.nocheyniebla.org/ wp-content/uploads/u1/56/56.pdf

González, J. J. (2007). Los paramilitares y el colapso estatal en Meta y Casanare. En M. Romero (Ed.), Parapolítica: la ruta de la expansión paramilitar y los acuerdos políticos (pp. 239-283). Corporación Nuevo Arco Iris.

Halbawchs, M. (1995). Memoria colectiva y memoria histórica. Reis, (69), 209-219. http://ih-vm-cisreis.c.mad.interhost.com/REIS/PDF/ REIS_069_12.pdf

Hernández, J. (2001 [1872]). Martín Fierro. ALLCA XX.

Hobsbawm, E. (1981). Bandits. Pantheon Books.

Jimeno, M. (1987). El poblamiento contemporáneo de la Amazonia. En Colombia Amazónica (pp. 213-233). Universidad Nacional de Colombia y Fondo FEN.

Lombana, M. (2012). La configuración espacial de Urabá en cinco décadas. Ciencia Política, 7(13), 40-79. https://revistas.unal.edu.co/index.php/ cienciapol/article/view/41511

López Castro, G. (1995). El río Bravo es charco: Cancionero del migrante. El Colegio de Michoacán.

Ludmer, J. (2000). El género gauchesco: un tratado sobre la patria. Libros Perfil.

Mahecha R., D. y Franky C., C. E. (2012). Los nükak, el último pueblo de tradición nómada contactado oficialmente en Colombia. En Pueblos indígenas en aislamiento voluntario y contacto inicial (pp. 202-245). Grupo Internacional de Trabajo sobre Asuntos Indígenas (IWGIA), Instituto de Promoción Estudios Sociales (IPES). https://bit.ly/3sN46xz. 
Marín Taborda, J. (2002). Colonización y recomposición campesina en el Guaviare 1960-1998. Memoria y Sociedad, 7(13), 117-158. https://revistas.javeriana.edu.co/index.php/memoysociedad/article/ view/7802/0

Medrano, R. y Castillo, A. (2016). Alias El Negro Acacio [El Halcón de Durango, intérprete]. En Corridos Prohibidos, Vol. 16 [CD]. Alma Producciones.

Mendoza, V. (1997). El romance español y el corrido mexicano: estudio comparativo. Universidad Autónoma de México.

Molano, A. (1987). Selva adentro: Una historia oral de la colonización del Guaviare. El Áncora.

Mora Calderón, P. (1998). Contribuciones al cancionero infame de Colombia. A Contratiempo, (10), 23-35. https://bit.ly/2OorSBi.

Páramo, C. (2009). Una música de frontera. En P. Vignolo (Ed.), Ciudadanías en escena: Performance y derechos culturales (pp. 221-227). Universidad Nacional de Colombia.

Pinzón, C. (2014). Compañero, los corridos se escriben con sangre: producción, circulación y narraciones alrededor de Corridos Prohibidos ${ }^{\circledR}$. [Tesis de Maestría, Universidad de los Andes, Bogotá, Colombia].

Redacción Colombia 2020. (3 de febrero de 2020). ¿Qué va a pasar con los espacios de reincorporación de las Farc que setrasladan? El Espectador. https://bit.ly/3ufH8zF

Ramírez Cardona, O. H. (2017, junio 8). Sentencia de la Sala Civil Especializada en Restitución de Tierras del Tribunal Superior de Bogotá. https://bit.ly/3rN6dAi

Sarlo, B. (2006). Tiempo pasado: Cultura de la memoria y giro subjetivo. Una discusión. Siglo XXI.

Semana (2001a, abril 9). Golpe maestro. Semana.com. https://bit.ly/31Mew4R

Semana (2001b, mayo 28). La confesión de Fernandinho. Semana.com. https://bit.ly/39ADg4g

Semana (2010, 8 de julio). Corridos Prohibidos: lo que sólo se dice cantando. Semana.com. https://bit.ly/3wrT1Vc 
Sierra, A. (2004, julio 25). En el corazón de la guerra paramilitar de los Llanos. El Tiempo.com. https:/www.eltiempo.com/archivo/ documento/MAM-1503142

Unidad para la Atención y Reparación Integral a las Víctimas (2017, marzo 29). En Guaviare, más de 150 personas fueron notificadas como sujeto de reparación colectiva. https://bit.ly/3uopjyt

Unigarro, D. E. (2020). Los campesinos de la Amazonia noroccidental colombiana: entre la coca, el conflicto y la construcción de paz. Antípoda. Revista de Antropología y Arqueología, (40), 175-200. https:// dx.doi.org/10.7440/antipoda40.2020.08

Valbuena, C. (2006). El cartel de los Corridos Prohibidos. Alma Producciones.

Valbuena, C. (2007). Sobre héroes, monstruos y tumbas: los capos en el narcocorrido colombiano. Caravelle, (88), 221-243. https://www.persee. fr/ doc/carav_1147-6753_2007_num_88_1_3146

Valbuena, C. (2009). Jacques Gilard y el narcocorrido colombiano. Caravelle, (93), 41-48. https://www.jstor.org/stable/40855136.

Valencia, A. (2015, diciembre 16). Sentencia de la Sala de Justicia y Paz del Tribunal Superior de Bogotá. https://bit.ly/2PUxh3r

Vargas, F. (Director). (2005). El violín [Cinta cinematográfica]. Cámara Carnal Films.

Verdad Abierta (2016, septiembre 14). "Esta sí es la Colombia profunda". https://bit.ly/3fLiaUy.

Verdad Abierta (2018, octubre 8). "Se avecina un nuevo desplazamiento, esta vez por hambre y no por armas". https://verdadabierta.com/se-avecinaun-nuevo-desplazamiento-esta-vez-por-hambre-y-no-por-armas/.

Vila, P. (2001). Música e identidad: la capacidad interpeladora y narrativa de los sonidos, las letras y las actuaciones musicales. En A. M. Ochoa y A. Cragnolini (Eds.), Músicas en transición (pp. 15-45). Ministerio de Cultura de Colombia.

Visacovsky, S. E. (2007). Cuando las sociedades conciben el pasado como "memoria": un análisis sobre verdad histórica, justicia y prácticas sociales de narración a partir de un caso argentino. Antípoda. Revista de Antropología y Arqueología, (4), 49-74.

https://dx.doi.org/10.7440/antipoda4.2007.03 